conduct successful negotiations; create presentations of a project, a product, a product specifically for the specifics of thinking and perception of the customer; to organize panel discussions, plenary sessions, thematic sessions, round tables, exhibitions, show-shows; to provide electronic support for the forum (creation of Internet resources, registration forms), etc. In addition, communication with leading leadership specialists creates the unique atmosphere of leadership that directly contributes to the formation of leaders capable of predicting and responding adequately to changes that indicate both the economic and social challenges of the new time, take responsibility for their implementation, share authorities and delegate power-oriented, co-opted.

Originality. University-based business forums are a step towards the emergence of new generation universities - innovative universities that can provide training for professionals and teams capable of designing new activities and ensuring the transformation of existing corporations, industries and territories in line with the challenges of the time. Today, as you can see (analysis of official websites of universities), business forums are a common practice in the educational activities of universities. One of these business forums, which was organized and conducted on the basis of the University of Ukoopspilks "Poltava University of Economics and Trade", was the International Business Forum "The Territory of Success. Business and Education: Strategic Partnership ", which was the result of close cooperation of the scientific and pedagogical staff and administration of the University with business representatives (October 6, 2016).

Conclusion. Considering the business forum as a form of organization of training for future bachelors in management aimed at forming their leadership competence, the author proposes to focus on the following components:

Information component - studying the theoretical foundations of a wide range of disciplines in a professionally-oriented cycle (students receive relevant practical information, visiting "territories of success", panel discussions, round tables, etc.);

Practical-oriented component - activation of educational and cognitive activity of students on the implementation of tasks from educational practices, term papers, projects (use of the information for practical purposes);

Interactive component - a unique opportunity for future bachelors in management of communication with business representatives, leaders-leaders (dating, communication, conversation, storytelling, question-answer), etc.;

Leadership-management component - students learn to manage their own learning, life, achieve success in the future profession, gain knowledge about leaders, develop leadership skills, learn leadership skills (forming leadership competencies);

Organizational component - students learn to organize and conduct similar events (panel discussions, plenary sessions, thematic sessions, round tables, exhibitions, show-shows, etc.);

Computer-oriented component - students learn to provide electronic support for the forum (creation of Internet resources, websites, content filling websites, development of registration forms, electronic information materials, banners, booklets, etc.).

The author proposes the Program of the International Business Forum "The Territory of Success. Business and Education: Strategic Partnership ". Visit of business forums in the further professional activity of modern managers creates conditions for constant self-improvement, professional development, development of leadership competence and a guarantee of the possibility of continuous professional training throughout their lives.

Keywords: competence, leadership competence, manager, bachelor, university, leader, business forum.

Одержано редакиією 23.09.2018 Прийнято до публікаиї̈ 01.10.2018

DOI 10.31651/2524-2660-2018-14-66-72

ORCID 0000-0001-6814-4666

ПАІСКО Вамерій Іванович,

доктор педагогічних наук, професор,

Національний університет "Чернігівський комегіум» імені Т. Г. Шевченка e-mail: pliskoej@ukr.net

ORCID 0000-0002-0170-2616

\title{
БОНДАРЕНКО ВаАенТин Володимирович,
}

кандидат педагогічних наук, доцент,

Національна академія внутрішніх справ e-mail: guryavvb@ukr.net

УДК 377.36.091.3:351.74

\section{ВПАИВ СИСТЕМИ ПОЕТАПНОЇ ПІДГОТОВКИ НА РОЗВИТОК КОГНІТИВНОГО КРИТЕРІЮ ПРОФЕСІЙНОЇ ГОТОВНОСТІ МАЙБУТНІХ ПРАЦІВНИКІВ ПАТРУМЬНОї ПОАІЩІї}

у статті висвітлено експериментальну перевірку впливу запропонованих новаиій системи поетапної підготовки на динаміку показників когнітивного критерію професійної готовності майбутніх праиівників патрульної поліuіï. У експерименті брали участь слухачі курсу первинної професійної підготовки поліиейсъких Наиіональної академії внутрішніх справ ( $n=61)$. Слухачі KГ (n=30) навчалися за чинною професійною програмою, ЕГ (n=31) - відповідно до розробленої системи поетапної підготовки, ио реалізовувалася завдяки иілеспрямованому ро- звиткові професійно важливих якостей; застосуванню ситуаиійних завдань під час опанування тактичної $i$ вогневої підготовок; використанню варіативних ситуаиійних задач під час проходження рольових ігор (сиенаріїв).

математичне опраиювання результатів тестування слухачів ЕГ на формувальному етапі педагогічного експерименту засвідчило достовірне підвищення більшості досліджуваних показників (p<0,05). Такі результати дають підстави стверджувати про позитивний вплив запропонованих новацій на розвиток показників 
когнітивного критерію професійної готовності майбутніх поліиейсъких.

ключові слова: когнітивний критерій; профресійна готовність; профресійна підготовка; патрульна поліиіі.

Постановка пробцеми. Правоохоронна діяльність, як і будь-який інший вид трудової діяльності мюдини, передбачає оволодіння певними теоретичними i прикладними основами, необхідними для ii успішного здійснення. Наукове їх обгрунтування вимагає цілеспрямованого вивчення специфіки діяльності підрозділів патрульної поліції, визначення змісту, структури, а також вимог, які висуваються до працівників. Подібний підхід дозволяє чітко окреслити як сферу професійної діяльності правоохоронця, так і обсяг службової інформації, засвоєння якої потрібне дмя ефективного виконання службових завдань.

Необхідні професійно-теоретичні знання майбутні працівники патрульної поліції здобувають під час навчання на курсах первинної професійної підготовки поліцейських [1, с. 16], а в подальшому поглиблюють під час професійної діяльності та навчальних занять у системі службової підготовки [2, с. 4]. Розширення функцій патрульної поліції, значна кількість службових завдань, підвищені вимоги до якісного їх виконання при чіткому дотриманні законності і повазі прав громадян підвищують роль професійних знань.

Аналіз службових ситуацій, що виникали під час професійної діяльності працівників патрульної поліції свідчить про низьку ефективність застосування набутих знань [3, с. 25]. В складних ситуаціях дії поліцейських мали ситуативних характер, визначалися емоційним станом, зовнішніми обставинами й будувалися на підгрунті життєвого і професійного досвіду [4, с. $219 ; 5$, с. 24]. Значна частина професійно-теоретичних знань, якими озброюють майбутніх працівників патрульної поліції виявляються недоступними під час виникнення ситуації, пов'язаних із іх миттєвим застосуванням. Тобто існуюча система професійної підготовки не сприяє стійкому формуванню умінь використання набутих знань на практиці.

Аналіз останніх досліджень $i$ публікацій засвідчив наявність значної кількості наукових праць присвячених вивченню способів підвищення ефективності засвоєння професійних знань майбутніми фахівцями та можливостей формування на їх основі практичних умінь i навичок (I. А. Акуленко, С. П. Архіпова, С. В. Гаркуша, К. М. Гнезділова, С. С. Данилюк, С. О. Жима, Є. В. Кулик, Є. О. Аопатко, М. О. Носко, $\Lambda$. З. Пакушина, В. І. ПАіско, О. К. Проніков, О. М. Тогочинський, $\quad$ В. П. Шпак, Г. Х. Яворська та ін.).

За визначенням Г. Х. Яворської, професійні знання - це професійно важмива інформація, що стала надбанням свідомості фахівця. Володіючи знаннями, фахівець планує вирішення поставмених завдань, обмірковує способи здійснення службових функцій, вивчає проблеми, що виникли, намічає цілі i способи їх вирішення, готує рішення, вибирає способи дій, контролює й оцінює свою поведінку. Чим глибше й грунтовніше він розуміє все це, тим вище його професіоналізм та ефективніша службова діяльність [6]. Знання є головною складовою в структурі професійної готовності майбутнього правоохоронця [7, с. 102]. Саме 3 достатнім обсягом доступних суб'єктові професійних знань, можливістю їхного засвоєння, опрацювання та розширення співвідноситься стан і рівень розвитку готовності до діяльності. Знання $є$ операційною складовою готовності та залежать від професійних функцій спеціаліста [8].

Численними науковими працями доведено, що ефективність засвоєння професійних знань буде найвищою за умови тісного поєднання теоретичної підготовки та практики $[9 ; 10]$. За свідченнями науковців освітній процес повинен мати чітку професійну спрямованість і сприяти актуалізації важливих дмя майбутніх фахівців професійних мотивів. Тобто система професійного навчання працівників патрульної поліції повинна ефективно поєднувати теоретичне та практичне навчання й сприяти формуванню умінь діяти в складних умовах не за стереотипом, а відповідно до ситуації, що складається та рівня небезпеки [7; 11]. Як відзначає I. М. Козцовська, застосування знань у нестандартних ситуаціях - це не особливе, відокремлене 
від знання уміння, воно виявцяється в умінні розкривати його за допомогою вже засвоєних дій, але за новим алгоритмом їх побудови [12, с. 141].

Практична спрямованість освітнього процесу на курсах первинної професійної підготовки поліцейських досягається шляхом вирішення ситуаційних задач під час відпрацювання здобутих практичних навичок патрульного поліцейського (проходження сценаріїв). При виконанні ситуаційних задач слухачі занурюються в умови максимально наближені до реальної професійної діяльності [10, с. 99]. Підбір і розроблення ситуаційних задач, що максимально відповідають особливостям службової діяльності сприятиме ефективнішому формуванню умінь та професійно важмивих якостей майбутніх правоохоронців.

Грунтовний аналіз спеціальної мітератури $[3 ; 5 ; 6 ; 8 ; 13 ; 14]$ дає підстави трактувати поняття "професійна підготовка майбутніх працівників патрульної поліції" як цілеспрямований і системний процес набуття слухачами професійнотеоретичних знань, формування професійно-практичних умінь і навичок, розвиток сукупності професійно важливих якостей, визначених специфікою правоохоронної діяльності й подальше їх оновцення і вдосконалення у процесі службової діяльності та занять у системі службової підготовки поліцейських. Відповідно професійна готовність працівника патрульної поліції - це стан особистості, який дозволяє здійснювати службову діяльність на належному професійному рівні та інтегрує в собі низку компонентів (професійно-теоретичну, психологічну, фізичну, тактичну готовність та готовність до застосування вогнепальної зброї) зі спроможністю оперативно їх поєднувати, постійно оновлювати, накопичувати і розвивати.

Мета роботи. Визначити вплив системи поетапної підготовки на розвиненість показників когнітивного критерію професійної готовності майбутніх працівників патрульної поліції.

Методи доспідження: теоретичні (аналіз, синтез, класифікація, узагальнення, моделювання); емпіричні (тестування, бесіди з викладачами, інструкто- рами й працівниками патрульної поліції, педагогічне спостереження, педагогічний експеримент.); методи математичної статистики.

Викцад основного матеріалу досаідження. Вивчення нормативних документів, особливостей службової діяльності патрульної поліції, грунтовний аналіз ситуацій у яких працівники зазнавали труднощів слугували підставами для удосконалення освітнього процесу майбутніх працівників патрульної поліції та розроблення системи поетапної підготовки. Мета новітньої системи - формування професійної готовності слухачів до ефективного виконання службової діяльності та підтримання i удосконамення іiі під час служби в поліції. Новаціями розробленої системи є: 1) цілеспрямований розвиток професійно важмивих якостей (фізичних, психологічних, комунікативних); 2) застосування ситуаційних завдань під час опанування навчальних предметів професійнопрактичної підготовки та під час занять у системі службової підготовки поліцейських; 3) використання варіативних ситуаційних задач під час проходження рольових ігор (сценаріїв). Зважаючи на те, що професійна готовність працівника патрульної поліції - це комплексна характеристика, об'єктивне оцінювання рівня іï сформованості передбачає виокремлення низки критеріїв, які б якісно і кількісно ї характеризували. Системою поетапної підготовки передбачено оцінювання рівнів сформованості професійної готовності слухачів i працівників патрульної поліції за чотирма критеріями: мотиваційно-ціннісним, когнітивним, операційно-діяльнісним, особистісним. Кожен критерій оцінюється за рівнем розвиненості низки показників.

Вияв впливу запропонованих новацій на розвиненість показників когнітивного критерію професійної готовності майбутніх працівників патрульної поліції передбачав проведення педагогічного експерименту. Дия цього створено експериментальну ЕГ $(n=31)$ і контрольну групи КГ ( $n=30)$ зі слухачів курсу первинної професійної підготовки поліцейських центру первинної професійної підготовки "Академія поліції" 
Національної академії внутрішніх справ. Педагогічний експеримент тривав упродовж опанування курсу спеціалізації (чотири місяці). Під час навчання осіб ЕГ реалізовувалися основні положення розробценої системи поетапної підготовки. Особи КГ навчалися відповідно до чинної професійної програми.

Виявлення рівня розвиненості когнітивного критерію професійної готовності передбачало визначення трьох показників: 1) "Знання законодавчого блоку; 2) "Знання з тактичної підготовки»; 3) "Знання 3 вогневої підготовки". Рівень розвиненості цих показника визначався мише на формувальному етапі педагогічного експерименту. Це пов'язано 3 відсутністю в слухачів спеціальних професійних знань на початковому етапі педагогічного експерименту.

Розвиненість показника "Знання законодавчого блоку" визначено шляхом аналізу результатів компцексного екзамену, під час здачі якого слухачі вирішували тестові завдання зі спеціалізації (три блоки по 20 питань у кожному). Загалом слухачам необхідно було вирішити 60 тестових завдань. Тести були конфіденційні й містили перелік питань по загальноправових предметах (службове документування; порядок складання адміністративних матеріалів та оформменню дорожньо-транспортних пригод; правові підстави затримання). Правикьна відповідь на кожне тестове завдання оцінювалося в один бал, неправильна - в нуль балів. При цьому мінімальний прохідний бал - 12 по кожному блоку питань. Дмя успішної здачі комплексного екзамену скухач повинен отримати щонайменше 36 балів. Максимальна кількість балів - 60. Відповідно до цього нами було виокремлено рівні професійної готовності за цим показником: низькому рівню відповідав діапазон від 36 до 41 балів, задовільному від 42 до 47 балів, достатньому від 48 до 53 балів, високий рівень - від 54 до 60 балів.

Показник когнітивного критерію "Знання з тактичної підготовки" також визначався тестуванням. Тестові завдання розроблено відповідно до тематики навчального предмета "Тактична підготовка", що опановувався впродовж навчання на курсах первинної професійної підготовки поліцейських. Загальна кількість питань - 60. Кожна правильна відповідь оцінювалася в один бал, неправильна - в нуль балів. Рівні професійної готовності визначалися таким чином: низький рівень до 35 балів включно, задовільний від 36 до 42 балів, достатній від 43 до 51 балів, високий рівень - від 52 до 60 балів.

Визначення рівня розвиненості показника "Знання з вогневої підготовкш" передбачало вирішення 60 тестових завдань, що містили три блоки: 1) правові підстави і порядок застосування (використання) вогнепальної зброї; 2) заходи безпеки при поводженні з вогнепальною зброєю; 3) матеріальна частина вогнепальної зброї. Критерії оцінювання анамогічні попередньому показнику.

Аналіз результатів визначення показника "Знання законодавчого блоку" дає підстави констатувати не значну різницю $(p>0,05)$ у підготовленості слухачів ЕГ і КГ (табл. 1).

Розвиненість показників когнітивного критерію в осіб ЕГ і КГ, бали

\begin{tabular}{|l|c|c|c|c|}
\hline \multirow{2}{*}{ Показники } & ЕГ $(n=31)$ & \multicolumn{2}{|c|}{ КГ $(n=30)$} & \multicolumn{2}{c|}{ Рівень значущості } \\
\cline { 2 - 5 } & $X \pm m$ & $X \pm m$ & $t$ & $P$ \\
\hline Знання законодавчого блоку & $48,5 \pm 0,90$ & $47,1 \pm 0,93$ & 1,082 & $>0,05$ \\
\hline Знання з тактичної підготовки & $49,8 \pm 1,06$ & $44,3 \pm 0,92$ & 3,919 & $<0,05$ \\
\hline Знання з вогневої підготовки & $49,3 \pm 1,10$ & $45,0 \pm 0,98$ & 2,919 & $<0,05$ \\
\hline
\end{tabular}

Середній бал осіб ЕГ становив $48,5 \pm 0,90$ бала із 60 можливих та відповідав достатньому рівню професійної готовності за когнітивним критерієм. У КГ цей показник зафіксований

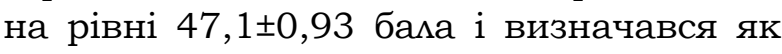

задовільний. Аналіз відповідей дав можмивість розподілити осіб ЕГ і КГ за рівнями професійної готовності відповідно до досліджуваного показника (табл. 2). 
Рівні сформованості професійної готовності осіб ЕГ і КГ за показниками когнітивного критерію, \%

\begin{tabular}{|c|c|c|c|c|}
\hline \multirow{2}{*}{ Група } & \multicolumn{4}{|c|}{ Рівні } \\
\hline & низький & задовільний & достатній & Високий \\
\hline \multicolumn{5}{|c|}{ "Знання законодавчого блоку" } \\
\hline $\mathrm{E} \Gamma(n=31)$ & 6,5 & 32,3 & 45,2 & 16,1 \\
\hline $\mathrm{K} \Gamma(n=30)$ & 13,3 & 30,0 & 40,0 & 16,7 \\
\hline \multicolumn{5}{|c|}{ "Знання з тактичної підготовки" } \\
\hline $\mathrm{E} \Gamma(n=31)$ & 3,2 & 9,7 & 45,2 & 41,9 \\
\hline $\mathrm{K} \Gamma(n=30)$ & 6,7 & 33,3 & 46,7 & 13,3 \\
\hline \multicolumn{5}{|c|}{ "Знання з вогневої підготовки" } \\
\hline $\mathrm{E} \Gamma(n=31)$ & 0 & 16,2 & 41,9 & 41,9 \\
\hline $\mathrm{K} \Gamma(n=30)$ & 3,3 & 30,0 & 46,7 & 20,0 \\
\hline
\end{tabular}

Згідно табличних даних в ЕГ зафіксовано $6,5 \%$ осіб із низьким рівнем професійної готовності, КГ - 13,3\%. Із задовільним - 32,3 \% осіб в ЕГ і 30,0 \% в КГ. Незначно відрізнялася кількість осіб із достатнім рівнем професійної готовності: 45,2 \% в ЕГ та 40,0 \% в КГ. Із високим рівнем $16,1 \%$ в ЕГ і $16,7 \%$ в КГ. Не суттєва різниця в розвиненості цього показника пояснюється перш за все тим, що пропонованою системою професійної підготовки передбачено більшою мірою опанування практичних знань, які необхідні для оперативного прийняття рішення стосовно застосування поліцейських заходів примусу в умовах службової діяльності та формування відповідних рухових умінь і навичок.

Математичне опрацювання результатів тестування показника когнітивного критерію "Знання з тактичної підготовкu” наприкінці педагогічного експерименту засвідчимо достовірну різницю у підготовленості осіб ЕГ і КГ $(p<0,05)$. Середній бал досліджуваного показника ЕГ на 5,5 бала перевищував представників КГ і становив $49,8 \pm 1,06$, КГ відповідно 44,3 $\pm 0,92$ (табл. 1). В обох групах рівень розвиненості показника оцінювався як достатній.

Аналіз індивідуальних відповідей дозволив розподілити піддослідних осіб за рівнями професійної готовності відповідно до досліджуваного показника (табц. 2). Згідно одержаних даних в ЕГ зафіксовано 3,2 \% осіб із низьким рівнем професійної готовності, КГ - 6,7\%. САухачів і з задовільним рівнем в ЕГ виявмено $9,7 \%$. Майже в тричі більше $(33,3 \%)$ осіб із задовільним рівнем готовності в КГ. Осіб із достатнім рівнем професійної готовності на формувальному етапі експерименту в ЕГ виявлено
$45,2 \%$ в КГ - 46,7\%. В тричі різнилася кількість осіб із високим рівнем професійної готовності: ЕГ - 41,9\%, КГ 13,3\%. Різниця в підготовленості пояснюється використанням в освітньому процесі слухачів ЕГ ситуаційних завдань, що сприяли якіснішому засвоєнню теоретичних знань з тактичної підготовки.

Показник когнітивного критерію "Знання з вогневої підготовки" на формувальному етапі експерименту також достовірно $(p<0,05)$ відрізнявся. Середній бал в осіб ЕГ становив 49,3 $\pm 1,10$, КГ -

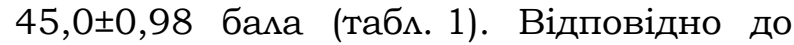
табличних даних (табл. 2) в ЕГ не виявмено осіб із низьким рівнем готовності, в КГ таких осіб - 3,3\%. Сцухачів із задовільним рівнем в ЕГ - 16,2\%, КГ $30,0 \%$. Осіб із достатнім рівнем в ЕГ виявцено 41,9\%, КГ - 46,7\%. Осіб із високим рівнем готовності в ЕГ 41,9\%, в КГ $20,0 \%$ (табл. 2). Такі результати також підтверджують позитивний вплив ситуаційних завдань і варіативних ситуаційних задач на якість засвоєння слухачами професійно-теоретичних знань стосовно застосування поліцейських заходів примусу під час опанування навчальних предметів професійно-практичної підготовки.

Висновки. На підставі проведених досліджень встановлено вплив запропонованих новацій системи поетапної підготовки на розвиток показників когнітивного критерію професійної готовності майбутніх працівників патрульної поліції. Математичне опрацювання результатів тестування осіб ЕГ і КГ свідчить про достовірну різницю в розвиненості показників "Знання з тактичної підготовки", "Знання з вогневої підготовкu” $(p<0,05)$. Такі результати дають 
підстави стверджувати про позитивний вплив застосованих новацій на розвиток показників когнітивного критерію професійної готовності майбутніх правоохоронців та ефективність системи поетапної підготовки.

Перспективи подамьших досліджень. Передбачається визначення впливу системи поетапної підготовки на розвиненість показників операційнодіяльнісного критерію професійної готовності майбутніх працівників патрульної поміції.

\section{Список бібліографічних посицань}

1. Бондаренко В. В. Специфіка первинної професійної підготовки інспекторів патрульної поліції. Науковий часопис Національного педагогічного університету імені М.П. Драгоманова. Серія № 15 : Науково-педагогічні проблеми фізичної культури (фізична культура і спорт). 2017. Вип. 5 (87) 17. С. 16-21. URL : http://elibrary.kubg.edu.ua/20349/1/Y_Tupitsya_ NCH_5_FZFVS.pdf.

2. Бондаренко В. В. Службова підготовка як складова системи професійного навчання працівників Національної поліції України. Науковий часопис Національного педагогічного університету імені М.П. Драгоманова. Серія № 15: Науковопедагогічні проблеми фізичної культури (фізична культура і спорт). 2017. Вип. 7(89) 17. С. 4-8. URL

http://enpuir.npu.edu.ua/bitstream/ 123456789 /20127/1/Bondarenko\%20V.V..pdf.

3. Бондаренко В. В. Теоретичні знання як складова підготовленості працівників міліції до ефективної діяльності в умовах протиборства із супротивником, озброєним холодною зброєю. Науковий часопис Національного педагогічного університету імені М.П. Драгоманова. Серія № 15: Науковопедагогічні проблеми фрізичної культури (фізична культура і спорт). 2014. Вип. 9 (50) 14. С. 24-28.

4. Бондаренко В. В. Ситуаційні моделі рухової та мотиваційної поведінки озброєного супротивника. Юридична психологія та педагогіка. 2013. № 2 (13). C. 217-226. URL: http://elar.naiau.kiev.ua/bitstream/123456789/44

5. Б4/1/24.pdf. ко В. В. , Михальчук Р. В. Особливості протистояння правопорушника й правоохоронця в різних умовах. Педагогіка, психологія та медикобіологічні проблеми фізичного виховання і спорту. 2013. № $1 . \quad$ C. 20-25. URL : https://cyberleninka.ru/article/n/osobennostiprotivostoyaniya-pravonarushitelya-i-rabotnikamilitsii-v-razlichnyh-usloviyah.

6. Яворська Г. Х., Рудницький В. Є. Професійна готовність до дій в нетипових ситуаціях у працівників особового складу спеціального підроздіку ОВС України. Наука $і$ освіта. 2013. № 1-2. С. 241-244.

7. Пиіско В. І., Бондаренко В. В. ААгоритм дій майбутнього офіцера міліції в умовах зіткнення зі змочинцем, озброєним холодною зброєю. Педагогіка, психологія та медико-біологічні проблеми фізичного виховання $i$ спорту. 2011. №2. С. 101104. URL: http://www.sportpedagogy.org.ua /html/journal/2011-02/11pvitcs.pdf.

8. Бондаренко В. В. Формування готовності до професійної діяльності працівників підрозділів патрульної поліції. Професійна освіта : методологія, теорія та технологї̈. 2017. С. 91-108.
9. Коваленко О. Е., Шматков Є. В., Брюханова Н. О., Короцьова Н. В. Методика професійного навчання. Харків, 2008. 488 с.

10. Бондаренко. В.В., Пронтенко К. В. Педагогічні умови застосування ситуаційних задач під час професійного навчання майбутніх працівників патрульної поліції. Наукові записки Тернопільського національного педагогічного університету імені Володимира Гнатюка. 2018. №1. C. 96-102. URL : http://catalog.library.tnpu.edu.ua/naukovi_zapusk u/pedagogic/2018/ped_1_2018_.pdf

11. Пиіско В. І., Носко М. О. Використання заходів фізичного впливу з тактичним осмисленням ситуацій відповідно до ступеня загрози : монографія. Чернігів, 2010. 284 с.

12. Козмовська I. М. Теоретичні проблеми інтегрування у професійному навчанні. Педагогічна і психомогічна наука в Україні. Збірник наукових праць. T. 5 : Неперервна професійна освіта: теорія $\mathrm{i}$ практика. 2007. С. 138-146.

13. ПАіско В. І. ШАяхи вирішення проблеми готовності правоохоронців до виконання службових обов'язків під час припинення змочинів. Педагогіка, психологія та мед.-біол. пробл. фріз. виховання i cnopmy. 2004. № 21. С. 49-56.

14. Кисленко Д. П. Сутність професійної підготовки майбутніх фахівців з охоронної діяльності на сучасному етапі. Вісник Черкаського університету. 2017. Вип. 10. С. 58-62.

\section{References}

1. Bondarenko, V. V. (2017). Specyfika pervynnoyi profesijnoyi pidgotovky inspektoriv patrulnoyi policiyi. Naukovyj chasopys Nacionalnogo pedagogichnogo universytetu imeni M. P. Dragomnova. Seriya № 15 : Naukovo-pedagogichni problemy fizychnoyi kultury (fizychna kultura i sport); (Scien??ific journal of the National Pedagogical University named after MP Drahomanov Series № 15 : Scientific and pedagogical problems of physical culture (physical culture and sports)), 5 (87), 16-21. Retrieved

http:/ / elibrary.kubg.edu.ua/20349/1/Y_Tupitsya_ NCH_5_FZFVS.pdf. (in Ukr.).

2. Bondarenko, V. V. (2017). Sluzhbova pidgotovka yak skladova systemy profesijnogo navchannya pracivnykiv Nacionalnoyi policiyi Ukrayiny. Naukovyj chasopys Nacionalnogo pedagogichnogo universytetu imeni M.P. Dragomanova. Seriya № 15 : Naukovo-pedagogichni problemy fizychnoyi kultury (fizychna kultura $i$ sport); Scientific journal of the National Pedagogical University named after MP Drhomanov Series № 15: Scientific and pedagogical problems of physical culture (physical culture and sports), 7 (89), 17 4-8. Retrieved from : http://enpuir.npu.edu.ua/bitstream/

123456789/20127/1/Bondarenko\%20V.V..pdf. (in Ukr.).

3. Bondarenko, V. V. (2014) Teoretychni znannya yak skladova pidgotovlenosti pracivnykiv miliciyi do efektyvnoyi diyalnosti $\mathrm{v}$ umovax protyborstva iz suprotyvnykom, ozbroyenym xolodnoyu zbroyeyu. Naukovyj chasopys Nacionalnogo pedagogichnogo universytetu imeni M.P. Dragomanova. Seriya № 15 : Naukovo-pedagogichni problemy fizychnoyi kultury (fizychna kultura $i$ sport); (Scientific journal of the National Pedagogical University named after MP Drahomanov Series № 15: Scientific and pedagogical problems of physical culture (physical culture and sports)), 9 (50) 14, 24-28. (in Ukr.).

4. Bondarenko, V. V. (2013). Sytuacijni modeli ruxovoyi ta motyvacijnoyi povedinky ozbroyenogo suprotyvnyka. Yurydychna psyxologiya ta pedagogika; (Legal psychology and pedagog), 217 226. Retrieved from : http://elar.naiau.kiev.ua/ bitstream/123456789/4464/1/24.pdf. (in Ukr.). 
5. Bondarenko, V. V., Prontenko, K. V., Prontenko, V. V., \& Myxalchuk, R. V. (2013). Osoblyvosti protystoyannya pravoporushnyka $\mathrm{j}$ pravooxoroncya $\mathrm{v}$ riznyx umovax. Pedagogika, psyxologiya ta medyko-biologichni problemy fizychnogo vyxovannya $i$ sportu; (Pedagogy, psychology and medicalbiological problems of physical education and sports), 1, 20-25. Retrieved from https://cyberleninka.ru/article/n/osobennostiprotivostoyaniya-pravonarushitelya-i-rabotnikamilitsii-v-razlichnyh-usloviyah. (in Ukr.).

6.

Yavorska, G. X., \& Rudnyczkyj, V. Ye. (2013). Profesijna gotovnist do dij v netypovyx sytuaciyax $\mathrm{u}$ pracivnykiv osobovogo skladu specialnogo pidrozdilu OVS Ukrayiny. Nauka i osvita; (Science and educaton), 1-2. 241-244. (in Ukr.).

7. Plisko, V. I., \& Bondarenko, V. V. (2011). Algorytm dij majbutnogo oficera miliciyi $\mathrm{v}$ umovax zitknennya zi zlochyncem, ozbroyenym xolodnoyu zbroyeyu. Pedagogika, psyxologiya ta medyko-biologichni problemy fizychnogo vyxovannya $i$ sportu; (Pedagogy, psychology and medical-biological problems of physical education and sports), 2, 101-104. Retrieved from: http://www.sportpedagogy.org.ua /html/journal/2011-02/11 pvitcs.pdf. (in Ukr.).

8. Bondarenko, V.V. (2017). Formuvannya gotovnosti do profesijnoyi diyalnosti pracivnykiv pidrozdiliv patrulnoyi policiyi. Profesijna osvita : metodologiya, teoriya ta texnologiyi; (Professional education: methodology, theory and technology), 91-108. - (in Ukr.).

9. Kovalenko, O. E., Shmatkov, Ye. V., Bryuxanova, N. O. \& Korolova, N. V. (2008). Metodyka profesijnogo navchannya. Xarkiv, 488 p. (in Ukr.).
10. Bondarenko, V. V. \& Prontenko, K. V. (2018). Pedagogichni umovy zastosuvannya sytuacijnyx zadach pid chas profesijnogo navchannya majbutnix pracivnykiv patrulnoyi policiyi. Naukovi zapysky Ternopilskogo nacionalnogo pedagogichnogo unive?sytetu imeni Volodymyra Gnatyuka; (Scientific notes of Ternopil National Pedagogical University named after Volodymyr Hnatyuk), 1, 96-102. Retrieved from http://catalog.library.tnpu.edu.ua/naukovi_zapusk u/pedagogic/2018/ped_1_2018_.pdf. (in Ukr.).

11. Plisko, V. I. \& Nosko, M. O. (2010). Vykorystannya zaxodiv fizychnogo vplyvu $\mathrm{z}$ taktychnym osmys?ennyam sytuacij vidpovidno do stupenya zagrozy. Chernigiv, 284 p. (in Ukr.).

12. Kozlovska, I. M. (2007). Teoretychni problemy integruvannya u profesijnomu navchanni. Pedagogichna i psyxologichna nauka $\mathrm{v}$ Ukrayini : Neperervna profesijna osvita: teoriya i praktyka; (Pedagogical and Psychological Science in Ukraine: Continuing Professional Education : Theory and? ractice), 5, 138-146. (in Ukr.).

13. Plisko, V. I. (2004). Shlyaxy vyrishennya problemy gotovnosti pravooxoronciv do vykonannya sluzhbovyx obovyazkiv pid chas prypynennya zlochyniv. Pedahohika, psykholohiia ta medykobiolohichni problemy fizychnoho vykhovannia $i$ sportu; (Pedagogy, psychology and medical-biological problems of physical education and sports), 21, 4956. (in Ukr.).

14. Kyslenko, D. P. (2017). Sutnist profesiynoyi pidhotovky maybutnikh fakhivtsiv $\mathrm{z}$ okhoronnoyi diyalnosti na suchasnomu etapi. Visnyk Cherkaskoho universytetu; (Cherkasy University Bulletin), 10. 58-62. (in Ukr.).

PLISKO Valerii,

Doctor in Pedagogy, Professor, National University T.H. Shevchenko "Chernihiv Collegium" e-mail: pliskoej@ukr.net

BONDARENKO Valentyn,

$\mathrm{PhD}$ in Pedagogy, Associate Professor, National Academy of Internal Affairs e-mail: guryavvb@ukr.net

\section{INFLUENCE OF THE SYSTEM OF POST TRAINING ON THE DEVELOPMENT OF COGNITIVE CRITERION OF PROFESSIONAL READINESS OF FUTURE EMPLOYEES OF PATROL POLICE}

Abstract. Introduction. A thorough analysis of the educational process of future law enforcement officers and situations that have arisen during the professional activity of the patrol police indicates a poor performance of the acquired professional knowledge. A significant amount of knowledge is inaccessible when situations arise with their instant use.

Purpose: to determine the influence of the system of phased training on the development of indicators of the cognitive criterion of professional readiness of future officers of the patrol police.

Methods: Theoretical (analysis, synthesis, class?fication, generalization, modeling); empirical (testing, interviews with teachers, instructors and police patrol staff, pedagogical observation, pedagogical experiment.); methods of mathematical statistics.

Results. The article analyzes the experimental verification of the impact of the proposed innovations of the phased training system on the dynamics of indicators of the cognitive criterion of professional readiness of future patrol police officers. The experiment was attended by undergraduates from the National Academy of Internal Affairs (n=61). Listeners of the control group $(n=30)$ studied according to the current professional program, experimental group $(n=31)$ - in accordance with the developed system of phased training, which was implemented due to the purposeful development of professionally important qualities (physical, psychological, communicative); application of situational tasks during mastering of tactical and fire preparations; the use of variation situational tasks during the passing of roleplaying games (scenarios). The mathematical analysis of the results of the testing of individuals of the experimental and the control group indicates a significant difference $(p<0,05)$ in the development of the indicators "Knowledge of tactical training", "Knowledge of fire training" abut not a significant difference in the indicator "Knowledge of the legislative bloc" $(p>0,05)$.

Originality. For the first time situational tasks were used that are used in the educational process during vocational training of students and contribute to consolidating the acquired theoretical knowledge and the formation of practical skills and skills in the use of police coercion measures. The content of the variation situational tasks used during scripting is improved.

Conclusion. The results of the conducted research give grounds for confirming the positive impact of the proposed innovations of the phased training system on the development of indicators of the cognitive criterion of professional readiness of future patrol officers and the effectiveness of the system of phased training.

Keywords: cognitive criterion, professional readiness, professional training, patrol police. 